www.jmscr.igmpublication.org

Impact Factor 5.84

Index Copernicus Value: 71.58

ISSN (e)-2347-176x ISSN (p) 2455-0450

crossref DOI: _https://dx.doi.org/10.18535/jmscr/v5i9.84

\title{
Multiple Myeloma in Young Patient: A Rare Case Report
}

\author{
Authors \\ Roshan Choudhary ${ }^{1}$, Indu Choudhary ${ }^{2}$ \\ ${ }^{1,2}$ Resident of Department of Pathology, Dr. S N Medical College
}

\begin{abstract}
Multiple myeloma, a disease of elderly, is extremely rare in those about 30 years of age. A patient with MM diagnosed at age 35 is described. He was a male with a four-month history of back pain and later, humerus and tibia pain persisting despite NSAIDS. X-rays had shown lytic lesions on lateral radiograph of the skull and the humerus. The Immunohistochemical examination demonstrated a strong reaction for the Lambda light chain in all tumor cells. . The presenting clinical and laboratory features are similar to those observed in patients of all ages who have myeloma.. The usual median age of myeloma is 65 years. A 35 year old patient presented with the history of anemia, bone pain and weakness. Despite the rarity of multiple myeloma among young patients, this diagnosis should be evoked when clinical, biological and radiological signs are in favor. This report illustrated that multiple myeloma should be even evoked in young patients.

Keywords: Multiple Myeloma, Young Person.
\end{abstract}

\section{Introduction}

Multiple Myeloma is a neoplastic plasma cell dyscrasia that is characterized by clonal proliferation of malignant plasma cells in the bone marrow microenvironment, monoclonal proteins in the blood or urine, and associated organ dysfunction. The hallmark features of multiple myeloma are highlighted by the acronym CRABcalcium elevation, renal insufficiency, anemia and bone disease. The median age at diagnosis is 65 years. Less than $2 \%$ of patients are younger than 40 years of age at diagnosis and it is extremely rare in those younger than 35 years. We report a case of multiple myeloma in a young patient aged 35 years.

\section{Case Report}

- A 35 year patient was referred to the Department of Pathology, Dr. S.N Medical
College, Jodhpur for bone marrow aspiration and biopsy. Patient had complaints of epistaxis, weakness and bone pain from last four-months. Patient also gave 4 months history of lumbar spine pain.

- On clinical examination, signs of anemia and lumbar spine tenderness were noted.

Peripheral blood smear examination showed pancytopenia and Rouleaux formation (figure 1).

- Laboratory examinations showed anemia, an increased erythrocyte sedimentation rate and hypercalcemia.

- Spine radiographs showed multiple lytic lesions.

- There was an M-band on serum protein electrophoresis (figure 4). The immunohistochemical examination demonstrated a strong reaction for lambda light chains in all tumor cells. 
- Bone marrow aspiration showed slightly hypocellular smears with hypercellular imprints. Erythropoiesis was normoblastic. Myelopoiesis was supressed and well represented. Abnormal cells - $65 \%$ of the nucleated cells appeared to be plasma cells, binucleate, multinucleate forms, and some intermediate forms were seen (figure $3)$.

- Bone marrow biopsy showed diffuse proliferation of plasma cells in the intertrabecular spaces. On RS staining reticulin fibers were increased.

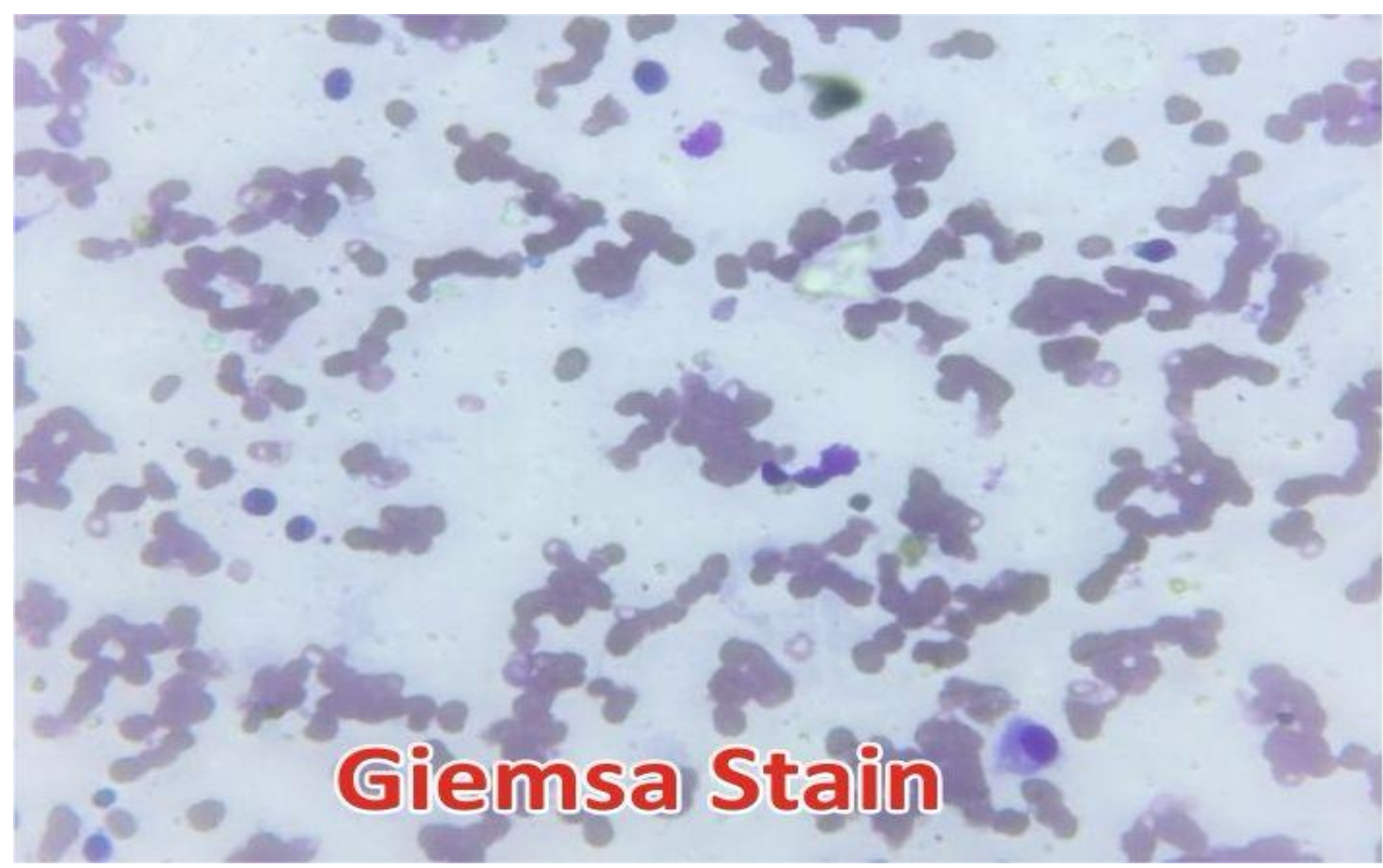

Figure 1- Peripheral blood film shows red cell rouleaux formation

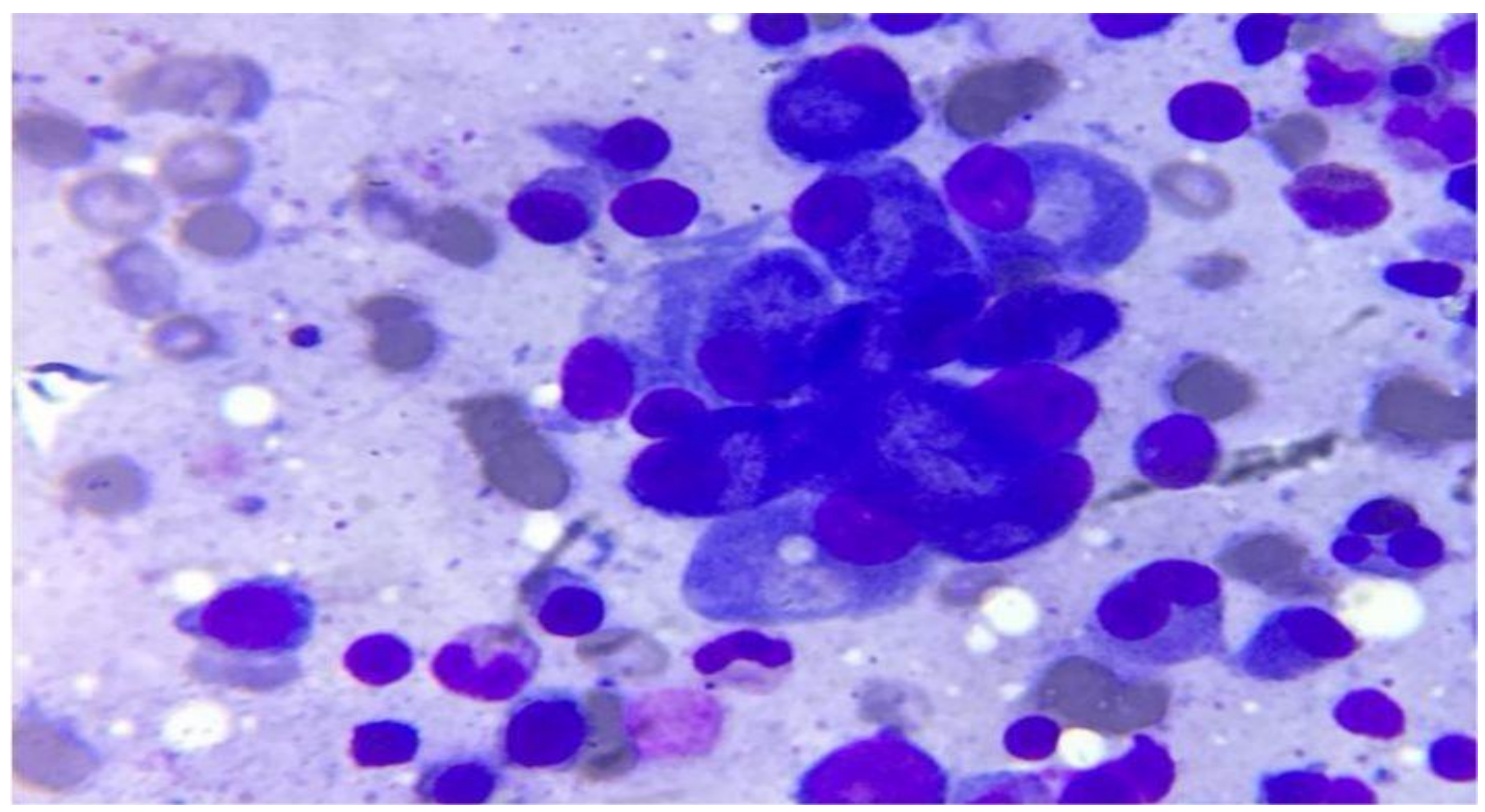

Figure 2. Bone marrow aspirate 


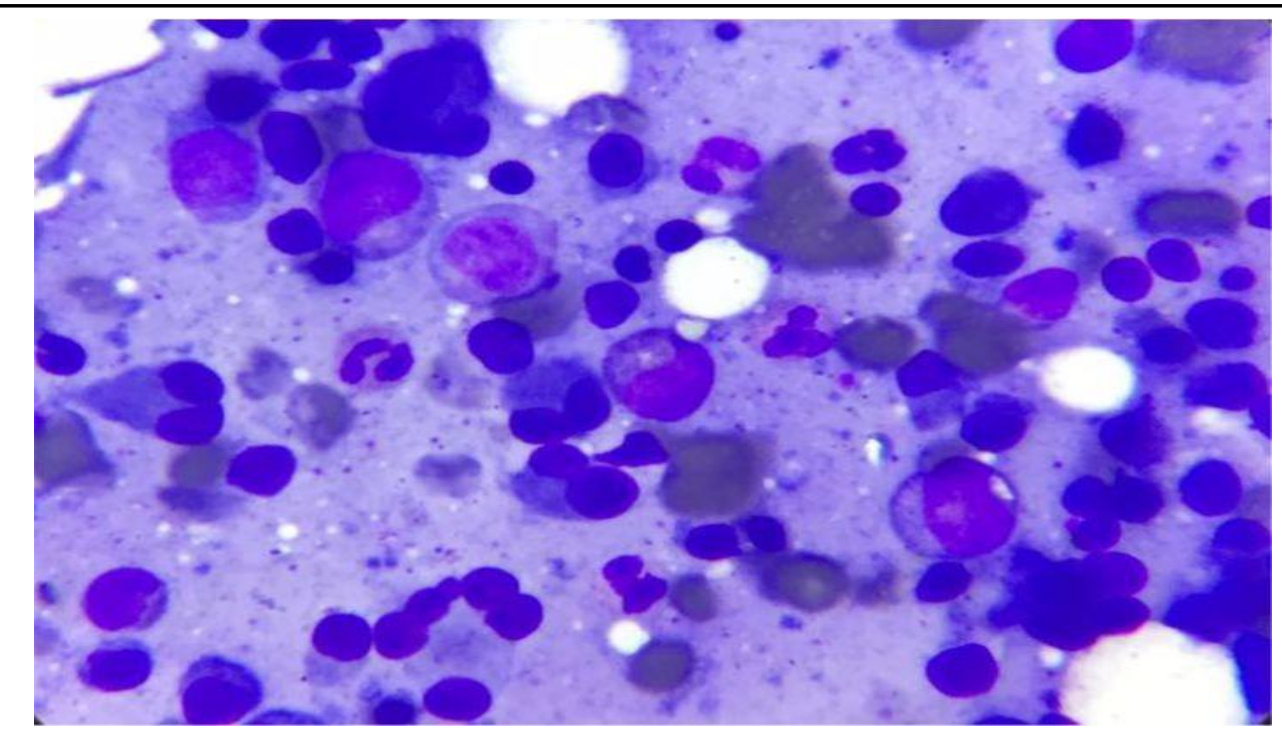

Figure 3 -Bone marrow aspirate showing plasma cells of multiple myeloma.

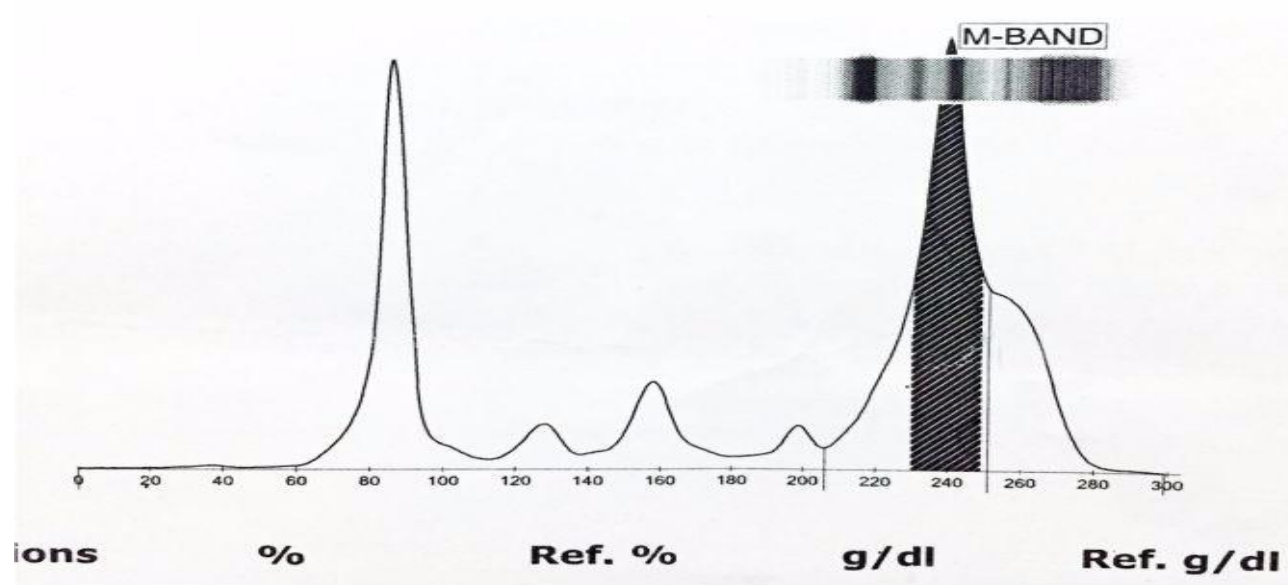

Figure 4- $\mathrm{M}$ band on Serum protein electrophoresis

\section{Discussion}

- $\mathrm{MM}$ is a malignant disorder which is characterized by the proliferation of monoclonal plasma cells. The peak incidence of MM is in the seventh decade, whereas, it is a rare entity in young patients, with less than $2 \%$ cases occurring in patients under the age of 40 years. Here we report a case of multiple myeloma in a young patient aged 35 years.

- Lazarus et al. reported two cases of plasma cell myeloma in young patients. One was a case of MM involving the skull and ribs in a 23-year-old woman; the other was a solitary myeloma of the tibia in a 21yearold man. Both the cases were diagnosed as non-secretory multiple myeloma. In our observation, there was an M-band in the serum protein electrophoresis. The Immunohistochemical examination demonstrated a strong reaction for the lambda light chains in all tumor cells.

\section{Conclusion}

Despite the rarity of multiple myeloma among young patients, this diagnosis should be evoked when clinical, biological and radiological signs are in favor. It appears that there is no difference between younger and elderly patients on the presentation of the disease, although a longer survival has been reported among younger patients. 


\section{References}

1. Antonio, P. and Kenneth, A. (2011) Multiple Myeloma. The New England Journal of Medicine, 364, 1046-1060.

2. Blade, J., Kyle, R.A. and Greipp, P.R. (1996) Multiple Myeloma in Patients Younger than 30 Years. Report of 10 Cases and Review of the Literature. Archives of Internal Medicine, 156, 14631468.

3. Ishida, T. and Dorfman, H.D. (1995) Plasma Cell Myeloma in Unusually Young Patients: A Report of Two Cases and Review of Literature. Skeletal Radiology, 24, 47-51.

4. Blade, J., Kyle, R.A. and Greipp, P.R. (1996) Presenting Features and Prognosis in 72 Patients with Multiple Myeloma Who Were Younger Than 40 Years. British Journal of Haematology, 93, 345351. 